\title{
The Primates 2016 Most-Cited Paper Award is conferred upon the following authors: M. F. Jaman and M. A. Huffman, G. Hanya et al., and M. LaFleur et al.
}

(C) Japan Monkey Centre and Springer Japan 2016

The three papers cited below were jointly the most frequently cited papers in 2015 among those published in Primates during the period from 2013 to 2014. Their authors thus contributed greatly to enhancing the reputation of our journal. For this achievement, each lead author will receive gifts from the Japan Monkey Centre, the Primate Society of Japan, and Springer. Co-authors will receive declarations attesting to their contributions.

10 July 2016

Tetsuro Matsuzawa: Executive Director, Japan Monkey Centre Editor-in-Chief, Primates

Masayuki Nakamichi: President, Primate Society of Japan

Peter Butler: Editorial Director, Springer

\section{References}

Jaman MF, Huffman MA (2013) The effect of urban and rural habitats and resource type on activity budgets of commensal rhesus macaques (Macaca mulatta) in Bangladesh. Primates 54:49-59

Hanya G, Tsuji Y, Grueter CC (2013) Fruiting and flushing phenology in Asian tropical and temperate forests: implications for primate ecology. Primates 54:101-110
LaFleur M, Sauther M, Cuozzo F, Yamashita N, Jacky Youssouf IA, Bender R (2014) Cathemerality in wild ring-tailed lemurs (Lemur catta) in the spiny forest of Tsimanampetsotsa National Park: camera trap data and preliminary behavioral observations. Primates 55: 207-217 